\title{
Children seen frequently out of hours in one general practice
}

\author{
Jillian M Morrison, Harper Gilmour, Frank Sullivan
}

\section{Abstract}

Department of General Practice, University of Glasgow, Woodside Health Centre, Glasgow G20 7LR Jillian M Morrison, MRCGP, general practitioner

Frank Sullivan, PHD, lecturer in general practice

Department of Public Health, University of Glasgow, Glasgow

Harper Gilmour, MSC, lecturer in statistics

Correspondence to: Dr Morrison.

BMf 1991;303:1111-4
Objective-To identify reasons why some children receive more out of hours visits than most.

Design-A one year prospective study to identify the study group. This was followed by a case-control study involving a record search and personal interviews.

Setting-One three doctor urban general practice in West Lothian with 4812 patients.

Subjects -40 children aged under 10 years identified as high users of the out of hours service (more than two visits a year) and $\mathbf{4 0}$ age and sex matched controls.

Main outcome measures-Numbers of visits; social factors such as lone motherhood, low educational attainment; score for management response to clinical vignette.

Results-147/756 (19\%) out of hours visits in the study year were to children aged under 10 years; $109(74 \%)$ to 41 children (6\%). Problems seen were mainly minor, and little active management was required. Family and social factors which were significantly more common for the cases than for the controls included a lone mother (15 $v$ 4), low educational attainment by the mother (25 $v 14)$, receipt of income support (22 $v 7)$, and non-ownership of the home (45 $v 22)$ or a car (19 $v 9)$. Mothers of the cases were more likely to choose to contact a doctor when presented with vignettes describing common childhood illnesses (median score for 16 vignettes 16.5 for cases $v$ 14.5 for controls, Wilcoxon signed rank test, $\mathrm{p}=\mathbf{0 . 0 1}$ )

Conclusions-Children seen more frequently than expected out of hours came from more socially disadvantaged families and their mothers were more likely to seek medical advice about minor childhood illness. Maternal education, to promote confidence in managing minor illness, may reduce their use of the out of hours service.

service, identifying reasons for their high use, and suggesting ways of modifying it.

\section{Methods}

The study was carried out in an urban practice of three doctors in West Lothian with a list size of 4812 at the midpoint of the study.

Out of hours visits were defined as all face to face contacts between doctor and patient between $6 \mathrm{pm}$ and $8 \mathrm{am}$, after $1 \mathrm{pm}$ on a Wednesday, after 12 noon on Saturday for the weekend, and on public holidays. Telephone contacts were excluded as we could not be sure that they were adequately recorded by the participating general practitioners. The out of hours work in this practice was shared with two neighbouring practices so that nine general practitioners (one working with a trainee) looked after about 18000 patients out of hours.

All out of hours visits performed in this general practice were recorded and analysed for one year from 1 November 1988 to 31 October 1989. The doctor on call completed a standard form which was passed to the practice concerned the next morning. The form included details of the date and time of the consultation; the name, address, and age of the patient; the name of the patient's own general practitioner; the nature of the problem, diagnosis, and action taken; and whether any follow up was required.

Children identified in this study as high users of the service out of hours - that is, receiving two or more visits in one year - were matched with other children in the practice of the same sex and age (within one month). The case records of the two groups were then searched for information about their consultation behaviour (excluding attendances for routine paediatric surveillance and immunisations) and physical health. To check that the controls were not presenting elsewhere with acute health problems, we sought evidence of attendance at the accident and emergency departments from the case records.

The mothers of all of the children were visited at

\section{Introduction}

Perhaps the most stressful aspect of a general practitioners's workload is out of hours work. ${ }^{1}$ Research has suggested that among those receiving house visits out of hours children are overrepresented ${ }^{2}$ but that few of the problems encountered are serious enough to merit hospital admission. ${ }^{3}$

Parental anxiety and a lower threshold among doctors for responding to requests for visits to children may mean that out of hours consultations for children will always be more frequent than their numbers in the population might warrant, but the general practitioners in the study thought that a small number of children were generating an excessive amount of the out of hours work. Doctors' impressions cannot always be trusted, ${ }^{4}$ so this study aimed at finding out whether there was indeed a group of children who were high users of the out of hours 
serious (2), fairly serious (1), not serious $(0)$. These scores were summed over the 16 vignettes to give each individual mother a total score. The preferred action was scored 2 if it meant consulting a doctor (in the accident and emergency department, in the surgery, or on a house call), 1 if it involved phoning the health visitor, and 0 if it did not include contact with a health professional.

Finally, the mothers' records were searched to find out about their consultation behaviour (excluding antenatal and postnatal appointments) and physical and mental health.

Statistical analysis was by Wilcoxon signed rank test for comparing medians of numerical variables which were not normally distributed-for example, the responses to the vignettes. The paired $t$ test was used for normally distributed variables, such as the age of the mother. McNemar's test was used for comparison of proportions. The Minitab statistical package was used to perform the statistical analysis. ${ }^{6}$ Confidence intervals for differences in proportions from paired samples were calculated using the Confidence Intervals Analysis statistics package.

\section{Results}

In the study year there were 756 out of hours visits in the practice-a rate of $157 / 1000$. There were 694 children in the practice aged under 10 years $(14 \%$ of the practice), and 147 of the out of hours visits were to children (19\% of visits). Forty one of the children had two or more visits, and these children received 109 of the 147 visits. Therefore $6 \%$ of children received $74 \%$ of the out of hours visits to children aged under 10 years. Forty (19 girls and 21 boys) of the 41 children were included in the study as one child moved out of the practice during the study year. The average age of the study group was 38.7 months. The peak age for visits was 6-30 months (see figure), but

TABLE I - Diagnosis in 107 consultations made out of hours by 40 study children

\begin{tabular}{lc}
\hline Condition & No \\
\hline Respiratory conditions & 56 \\
Upper respiratory tract infections & 29 \\
Lower respiratory tract infections (including bronchiolitis) & 3 \\
Asthma & 4 \\
Croup & 2 \\
Otitis media & 12 \\
Tonsillitis & 5 \\
Blocked nose & 1 \\
Gastrointestinal conditions & 20 \\
Diarrhoea and vomiting & 14 \\
Colic & 4 \\
Constipation & 1 \\
Non-specific abdominal pain & 1 \\
Accidents & 12 \\
Head injury & 8 \\
Fracture of distal phalanx & 1 \\
Sunburn & 1 \\
Sore foot & 1 \\
Foreign body in ear & 1 \\
Other & 19 \\
Rash including exanthemas & 7 \\
Maternal anxiety & 4 \\
Raised temperature-no obvious cause & 3 \\
Epistaxis & 1 \\
Teething & 1 \\
Conjunctivitis & 1 \\
Failure to thrive & 1 \\
Don't know & 1 \\
\hline
\end{tabular}

TABLE II - Management at 107 out of hours consultations

\begin{tabular}{lc}
\hline Management & No \\
\hline Reassurance or advice & 50 \\
Prescription issued & 31 \\
On the spot medication dispensed (antibiotic, paracetamol, or & 17 \\
electrolyte solution) & 4 \\
Hospital admission arranged & 2 \\
Referral for radiography & 2 \\
Laceration steristripped & 1 \\
Information not available &
\end{tabular}

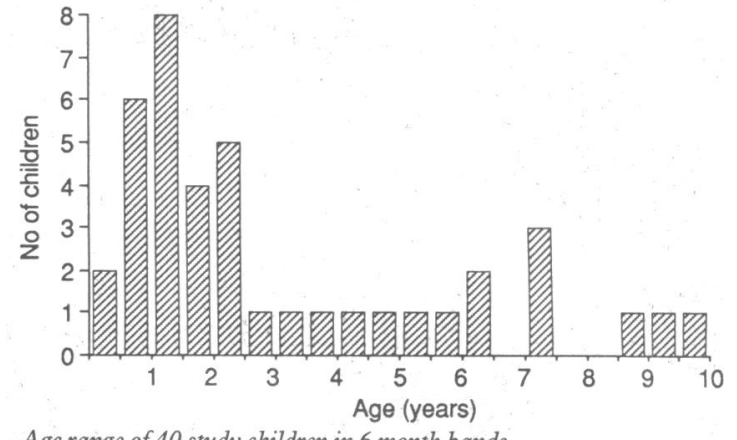

Age range of 40 study children in 6 month bands

children in this age group who were seen twice or more often out of hours were still in the upper fifth of this age group.

The problems encountered on the 107 visits to the study group are shown in table I and the management is given in table II. The median number of daytime consultations was five for the study group and three for the controls (Wilcoxon signed rank test, $\mathrm{p}<0.001$ ). According to the records five of the study group and two of the controls had been taken by their parents to the accident and emergency department during the study year. The accuracy of these figures was checked by comparing the practice records with a computerised printout of practice attenders obtained from the local casualty department. Over five months 187 patients in the practice had referred themselves to the accident and emergency department according to the computer printout and 184 letters were held in the patients' records (98\% agreement). Therefore the figures for attendance at the accident and emergency department among the children were likely to be accurate. A search of the children's records for evidence of physical ill health other than minor self limiting illness showed five problems among the study group and six among the controls.

The mean age of the mothers of the study children was 27 (range 18-36) and of the controls 29 (range 1945 ; paired $t$ test, $\mathrm{p}=0 \cdot 11$ ). There was no significant difference in median family size ( 2.0 for study group $v$ 2.0 for controls) or in the position of the index child in the family ( $23 v 18$ were the first child; McNemar's test, $\mathrm{p}=0 \cdot 30$ ).

The mothers of the study children were more likely to be single or divorced, to have attained a lower educational level, and to be receiving income support (table III). They were less likely to own their own home or a car. There was no significant difference in whether the mother or her partner was employed, whether there were close relatives living nearby, or whether their preschool children attended a nursery or other preschool group.

There was no difference between the mothers in the perception of whether they thought their children healthy ( 35 study children and 38 controls were thought to be healthy). There were also no differences in whether they perceived no problems in other family members ( 32 study group mothers and 36 controls), whether they perceived themselves to be healthy ( 32 and 31 ), and whether they perceived no problems in extended family members (31 and 35).

The mothers of the study children were not more likely to consider the vignette situations more serious than the mothers of the controls (median score 12 for cases and 11 for controls, Wilcoxon signed rank test, $p=0 \cdot 14$ ), but the mothers of the cases were significantly more likely to contact a doctor (Wilcoxon signed rank test, $\mathrm{p}=0 \cdot 01)$. The median score for the preferred action was 16.5 for the cases and 14.5 for the controls. When asked under what circumstances they would call a doctor out of hours all the mothers 


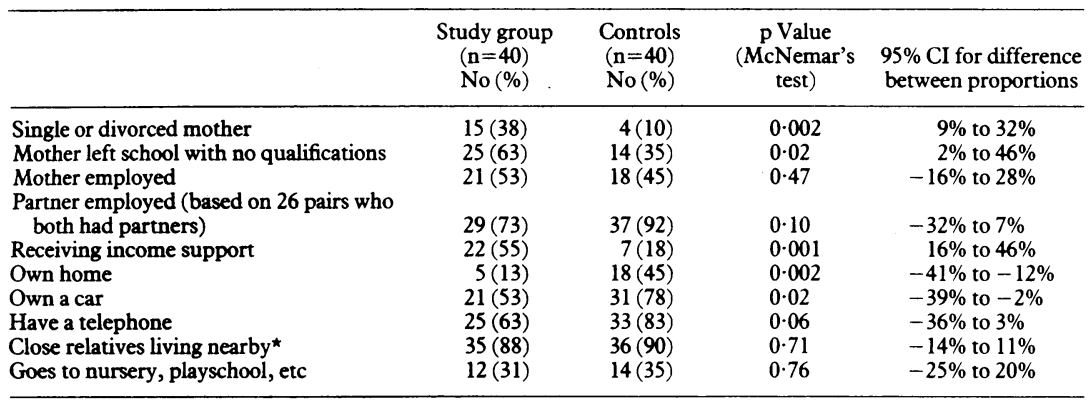

found that only $5 \cdot 1 \%$ of visits resulted in admission to hospital.

It has been suggested that the number of patients who seek medical advice out of hours is underestimated because more patients attend accident and emergency departments than contact their general practitioner. ${ }^{11}$ Our findings do not support this claim. On the contrary, few children in either the study or control group attended the accident and emergency department during the study year. Frequent attenders are also known to have more doctor defined physical illness than the rest of the community, ${ }^{10}$ and Campion and Gabriel found that serious health problems were the most important determinants of consulting patterns in their study of illness behaviour in mothers with young children. ${ }^{5}$ However, we found no difference in the number of doctor defined serious health problems between the study children and the controls.

Like others, we found a relation between social and economic status and frequent consultation. ${ }^{510}$ Before the study began we suspected that single mothers would be more likely to call a doctor out of hours, and our findings seem to support this. The absence of another adult in the household to consult about a child's illness may make the mother more likely to seek a second opinion from another source. For this reason we asked about the presence of close relatives nearby, but the practice is in a relatively closeknit community, so a similarly large proportion of the study group and controls had close relatives within about three miles of their home. Nevertheless, the option of discussing the problem with relatives, friends, or the chemist was infrequently chosen. The highest level of education reached was important.

Other factors that are important as social indicators might also be important in their own right. For example, owning a car may mean that ill children can be brought more easily to the surgery during the day. Although the presence of a telephone in the home might be expected to be positively associated with out of hours calls, this was not the case and mothers who are worried about their children out of hours seem able to gain access to a telephone.

Although both groups of mothers assessed the severity of the vignettes similarly, the mothers of the study children were significantly more likely to consult a doctor. This was similar to their response to real life childhood illness as these mothers presented their children more often for a medical opinion both during routine hours and out of hours. In their study Campion and Gabriel were more concerned about underconsulting due to lack of information or lack of concern by mothers than about overconsulting for trivia. In our study, however, only a small minority of the visits were for serious problems, few of the patients referred themselves to accident and emergency departments, and during the study year no children in the practice died or suffered serious illness as a result of delay in seeking medical help. Therefore underconsulting is unlikely to be an important problem at night.

Despite our findings we do not advocate that general practitioners should refuse to visit children who are seen frequently out of hours. If, however, it were possible to educate the mothers of these children to manage episodes of minor childhood illness themselves then they might become more confident about doing so. To this end the out of hours visit itself could be used as an opportunity to educate the mother, particularly if the problem is trivial. Tact is, however, required, as this study suggests that mothers do not contact the doctor out of hours unless they feel that the situation is serious. Bollam et al believed that patients would benefit from some indication of what the practice the morbidity pattern was comparable (upper respiratory tract infections followed by diarrhoea and vomiting were the most common conditions). Walker also 
considered to be appropriate use of the out of hours service. ${ }^{12}$ However, Usherwood has shown that written advice about particular childhood symptoms may increase out of hours visits. ${ }^{13}$ Other opportunities for advising mothers include paediatric assessment clinics, immunisation clinics, and routine surgery attendances. The health visitor is a valuable member of the team who is underused as a source of advice on the management of childhood illness ${ }^{14}-a$ finding confirmed by this study.

We thank Peter Campion for allowing us to use the vignette instrument; the Department of General Practice, University of Glasgow, for advice; and doctors, staff and patients who participated in the study. This study was supported by a grant from the Scientific Foundation Board of the Royal College of General Practitioners. These findings were reported at the Scottish University Departments of General Practice annual scientific conference on 25 January 1991.

1 Pitts J. Hours of work and fatigue in doctors. $\mathcal{F} R$ Coll Gen Pract 1988;38:2-3. Tulloch AJ. "Out of hours" calls in an Oxfordshire practice. Practitioner 1984;228:663-6.

Walker RD. Study of out-of-hours visits to children. $f(R$ Coll Gen Pract $1985 ; 35: 427-8$

4 Bhopal JS, Bhopal RS. Perceived versus actual consultation patterns in an inner city practice. $7 R$ Coll Gen Pract 1989;39:156-7.

5 Campion PD, Gabriel J. Illness behaviour in mothers with young children. Soc Sci Med 1985;20:325-30.

6 Minitab Inc. Minitab statistical software. Dayton: Mazer, 1986.

7 Gardner MJ, Altman DG. Statistics with confidence. London: BMJ, 1989.

8 Machin D, Campbell MJ. Statistical tables for the design of clinical trials. Oxford: Blackwell Scientific, 1987.

9 Pitts J, Whitby $M$. Out of hours workload of a suburban general practice: deprivation or expectation. BMF 1990;300:1113-5.

10 Westhead JN. Frequent attenders in general practice: medical, psychological and social characteristics. $\mathcal{F} R$ Coll Gen Pract 1985;35:337-40.
11 Williams DJ. Patient's assessment of out of hours care. BMJ 1988;296:1197. 12 Bollam MJ, McCarthy M, Modell M. Patients' assessment of out of hours care in general practice. $B M \mathcal{F} 1988 ; 296: 829-32$.

13 Usherwood TP. Development and randomised controlled trial of a booklet of advice for patients. Brf Gen Pract 1991;41:58-62.

14 Duncan JK, Taylor RJ, Fordyce IE. Factors associated with variation in the consultation rates of children aged under 5 years. $f R$ Coll Gen Pract consultation rates

(Accepted 12 July 1991)

\section{Correction}

\section{Funding family health services}

An editorial error occurred in this article by David Taylor. (7 September p 562.) Figure 2 should appear as below and not as printed.

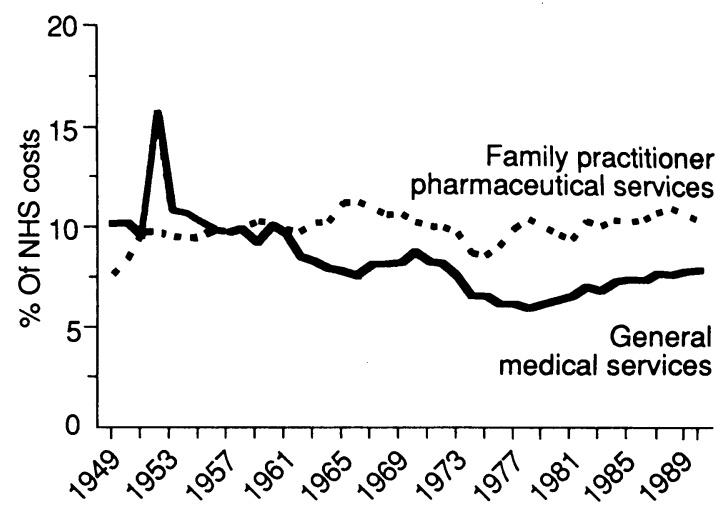

Western General Hospital in Edinburgh, was beginning his observations on dyspepsia which were to take him to the chair of medicine in relation to mathematics and computing at Glasgow and the start of the great study (with Crean, Knill-Jones, and others) of dyspepsia, the results of which I use, consciously and unconsciously, every working day. In Leeds de Dombal and his colleagues have used similar analyses to clarify the diagnosis of acute abdominal pain and other gastrointestinal problems. ${ }^{2}$ Wayne's principles - that symptoms and signs varied in their importance and in the degree of observer variation in their elicitation-have not been universally learnt. Nevertheless there is now a steady flow of papers questioning the dogma and ritual that we use in the diagnostic process. Unfortunately, many students and young doctors still seem to have learnt their technique of interrogation and examination by rote and produce sheets of history with no adequate attempt at rational deduction. The omnipresent computer - whose domination we dreadmay be an ally because it demands and aids accuracy.

What Sir Edward Wayne painstakingly worked out in the first half of this century may become accepted doctrine and universal practice by the beginning of the next.JOHN R BENNETT is a consultant physician in Hull

1 Wayne EJ. Clinical and metabolic studies in thyroid disease. $B M \mathcal{F}$ $1960 ;$; :1-11, 78-90.

2 De Dombal FT, Leaper DJ, Staniland JT, Horrocks JC, McCairn AP. Computer aided diagnosis of acute abdominal pain. $B M \mathcal{F}$ 1972;ii:9-13.
Like so many important lessons in medicine, even

\section{A PAPER THAT CHANGED MY PRACTICE}

\section{Symptomatic discrimination}

It might seem eccentric or eclectic for a gastroenterologist to claim that two papers on thyroid disease had a strong influence on his clinical practice. In reality it is because Sir Edward Wayne's Lumleian lectures, while summarising many of his life's studies into thyroid disease, particularly emphasised the difficulty in some cases of making an accurate clinical diagnosis in the days before radio immunoassay. ${ }^{1} \mathrm{He}$ showed how analysis of the incidence of certain symptoms and physical signs in disease compared with normal would allow a discriminant value to be placed on each symptom or sign and eventually a score assigned which could lead to an accurate diagnosis.

My interest was aroused by his papers for two reasons. I had spent some time in a large thyroid clinic at Liverpool's David Lewis Northern Hospital and so was familiar with the diagnostic problems. I was also developing my lifelong scepticism, and already doubted those clinicians who claimed the ability to adduce an impressive diagnosis on the basis of a single, arcane symptom or sign. Wayne's clear prose not only helped me with thyroid disease but showed that all symptoms and signs in clinical medicine needed to be weighed and measured.

Of course, Wayne acknowledged that experienced and competent clinicians had always recognised the varying importance of different signs and symptoms, and great teachers (Sydenham, Osler, and Richard Asher are three I have read with benefit) have said as much. Even as Wayne gave his lectures others were working on the same lines. Wilfred Card, with his large gastrointestinal clinic at the 